\title{
Educados no sexo neutro: a construção discursiva de sexualidade e de gênero em um texto da revista Veja
}

Educated in Neutral Gender: the Discursive Construction of Sexuality and Gender in a Veja Magazine Article

Dánie Marcelo de Jesus*

Universidade Federal de Mato Grosso

Cuiabá - Mato Grosso

RESUMO: Neste artigo, analisamos o texto "Educados no sexo neutro", publicado na revista Veja, a fim de compreender como ele constrói, discursivamente, o sentido de masculinidade e de feminilidade. A análise se insere numa perspectiva crítica do discurso (FAIRCLOUGH,1992/2001), apoiada nos estudos sobre gênero e sexualidade (SEDWICK, 1990/2008, LOURO, 2000; MOITA LOPES, 2002; 2006; 2009; BUTLER, 1990/2006). Os resultados demonstram a predominância de um discurso essencialista de identidade sexual apoiado em uma visão hegemônica heteronormativa que procura descrever os indivíduos dentro de um espaço social binário.

PALAVRAS-CHAVE: discurso, sexualidade e gênero.

ABSTRACT: This paper examines the article "Educados no sexo neutro" ("Educated in neutral gender", in English), published by the Brazilian magazine Veja, in order to understand how it discursively constructs the meaning of masculinity and femininity. The analysis is grounded on a critical discourse approach (FAIRCLOUGH, 1992/2001), supported by studies on gender and sexuality (SEDWICK, 1990/2008; LOURO, 2000; MOITA LOPES, 2002; 2006; 2009; BUTLER, 1990/2006). Findings suggest the predominance of an essentialist discourse of sexual identity based on a hegemonic heteronormative view, which seeks to describe individuals within a binary social space.

KEYWORDS: discourse, sexuality, gender.

*daniepuc@gmail.com 


\section{Introdução}

Nos últimos anos, tornaram-se cada vez mais comuns estudos sobre a relação gênero-linguagem-sexualidade (SEDWICK, 1990/2008, LOURO, 2000; MOITA LOPES, 2002; BUTLER, 1990/2006; HIGHTOWER, 2009/2011,JESUS, 2012a, 2012b), revelando a complexidade social e política dessa temática no contexto contemporâneo. Tais reflexões nos induzem a discussões relativas à imagem da feminilidade e da masculinidade em nossa sociedade e ao efeito dela em nossa interação cotidiana.

Essas imagens inevitavelmente se dão pelo discurso, entendido como forma de prática social ${ }^{1}$ (FAIRCLOUGH, 1992/2001), que define nossas relações com o outro e nossos posicionamentos sociais. Moita Lopes (2009, p. 15) considera que "nós somos os discursos em que circulamos: eles nos fazem e constroem, ou seja, a linguagem não nos representa simplesmente, mas nos constrói”. Esses discursos são convencionalmente desenvolvidos dentro de um contexto sócio-histórico que ritualiza nossas açōes performáticas (BUTLER, 1990/2006). É por essa convenção que normas de identificação dos sujeitos são estabelecidas. Contudo, esse processo não é completamente obtido. Daí a necessidade de tais normas serem peremptoriamente reconhecidas para que possam exercer seus efeitos.

É por essa perspectiva da linguagem à luz de alguns princípios da teoria queer, tais como sexo, sexualidade, gênero, performatividade, heteronormatividade, associados à noção de discurso advinda dos trabalhos de Fairclough (1992/2001), que procuramos desenvolver a pesquisa em pauta.

Este artigo se propõe, portanto, investigar o texto intitulado: "Educados no sexo neutro: uma corrente pedagógica defende a tese de que meninos e meninas devem ser criados de forma igual. O perigo é confundi-los acerca de sua sexualidade". Escrito por Fernanda Allegretti, foi ele publicado, em 19 de dezembro de 2012, na revista Veja. O cerne de nossa análise está centrado no discurso sobre a questão de gênero e sexualidade que permeia essa publicação. $\mathrm{O}$ mote que originou o texto da revista se deu em decorrência da propaganda de filiais das lojas de brinquedos Toys"R"Us e BR Toys, na Suécia. Traziam em seu catálogo de Natal, em 2012, fotos ilustrativas de meninas com carrinhos e armas, enquanto meninos se divertiam com bonecas e utensílios domésticos.

\footnotetext{
${ }^{1}$ Prática social é compreendida, neste trabalho, como toda experiência social que um sujeito vivencia em suas interaçóes cotidianas. Por exemplo, ajoelhar-se em oração em uma igreja.
} 
Em adendo, o texto intenta discutir posicionamentos pedagógicos que procuram não diferenciar a categoria de gênero feminino e masculino.

A análise se baseia na relação entre discurso e sexualidade apresentada no texto da revista com o objetivo de responder à seguinte questão: como se dá a construção discursiva de sexualidade e de gênero no texto da revista? Para esquadrinhar o referido texto, buscaram-se parâmetros analíticos e metodológicos nos estudos sobre discurso (FAIRCLOUGH, 1992/2001) e alguns princípios dos estudos queer com a finalidade de entender a construção discursiva de gênero que se mostra no discurso da reportagem da revista. Ao concluir, procuro refletir na importância da pesquisa sobre gênero e sexualidade na mídia, bem assim em suas consequências políticas e educacionais no âmbito dos estudos relativos à linguagem.

\section{Linguagem e estudos queer}

Com o advento da teoria queer, alguns pesquisadores (LIVIA; HALL, 2010; MOITA LOPES, 2002) dos estudos de linguagem começam a se interessar em compreender as bases do discurso hegemônico de heteronormatividade, separando sexo biológico de práticas sociais de gênero. Essa inquietante posição teórica procura levar em consideração relações de gênero para repensar as condições de fronteira entre eles, demonstrando a volatilidade dos indivíduos que podem se identificar com categorias identitárias diversas, notadamente estas: lésbicas, bissexuais, travestis, transexuais, heterossexuais, homossexuais, transgêneros.

A esse respeito, Weeks (1999) nos esclarece que sexo deve ser entendido como termo que descreve as diferenças anatômicas internas e externas do corpo, geralmente dadas no ato do nascimento. Em contrapartida, que o termo gênero, ainda segundo Weeks (1999), refere-se à diferenciação social que atribui papéis culturais e históricos ao posicionamento dos sujeitos, independentemente de qualquer base biológica. Já sexualidade, de acordo com o mesmo autor, é apresentada como descrição geral para uma série de crenças, comportamentos, relações e identidades socialmente construídas.

Sedwick (1990/2008), por sua vez, considera que a separação entre sexo e gênero é elemento-chave na compreensão contemporânea sobre sexualidade. A autora, contudo, adverte que a discussão em torno da questão de gênero não deve ser marcada apenas pelo heterossexismo (oposição homens versus mulheres), tampouco pelos estudos minoritários (gays e lésbicas). Segundo ela, a díade homo/heterossexualidade não mais aflora como uma 
oposição excludente, mas principalmente relacionada. Assim, procura-se salientar a heteronormatividade (WARNER, 1991) como um conjunto de prescrições sociais que organiza, regula e controla o comportamento social, mesmo daqueles que se denominam heterossexuais.

Dentro dessa perspectiva, Butler (1990/2006) afirma que todo gênero se apresenta como performativo. Quer isso dizer que toda construção de identidade é sempre um fazer-ser ou que simula ser. Como exemplo, imaginemos o pronunciamento de uma parteira no nascimento de uma criança: "É uma menina". A criança é inscrita no status feminino ao ser assim enunciada. Desse modo, o gênero é demonstrado por meio de atos que fazem existir aquilo que é designado. As identidades de gênero, nesse caso, são construídas e constituídas pela linguagem, ou seja, não existe identidade de gênero que preceda a linguagem. É nesse sentido que gênero é performativo. Por essa razão, o sujeito está sempre envolvido num processo de devir sem fim, podendo reassumir ou repetir sua performatização de diferentes maneiras.

Por esse pressuposto, Butler (1990/2006) empreendeu investigações que procuram desconstruir as categorias de feminino e de masculino, afirmando a indeterminação e a instabilidade de todas as identidades sexuadas. Em vez de supor que as identidades são autoevidentes e fixas, ao modo como fazem os essencialistas, o trabalho de Butler descreve os processos pelos quais a identidade é construída no interior da linguagem e do discurso. O sujeito não existe desde o nascimento, mas é instituído em contextos específicos. Então, o sujeito pode ser instituído diferentemente, sobre formas que não se limitem a reforçar as estruturas de poder existentes.

Gênero, portanto, é um processo que não tem origem nem fim, é algo que "fazemos", e não algo que "somos". Pensando dessa forma, gênero é um ato ou uma sequência de atos que está sempre e inevitavelmente ocorrendo, já que é impossível alguém existir como agente social fora dos termos do gênero. Assim, por esse viés, corpos, sexualidades e gêneros são entendidos como construções sociais e históricas marcadas pelas relações de saber-poder, sempre restritas ao contexto em que essas relações são estabelecidas.

Essa perspectiva epistemológica admite multiplicidade de sentido para a expressão da feminilidade e da masculinidade, mas não nega as relações de poder inerentes à linguagem. Instaura-se, em consequência, uma discussão crítica que procura fissuras na ordem social essencialista, demonstrando que as práticas identitárias são complexos processos histórico-sociais situados, cujos indivíduos são constantemente reinterpretados por seus interlocutores. É em 
decorrência dessa situação que as pessoas são definidas como pertencentes a determinados espaços sociais. Essa localização quase sempre é construída por meio da negação das diferenças, fruto de um pensamento dicotômico que procura justificar a supremacia de um grupo sobre outro (HALL, 1997/2000).

Tal oposição binária se revela por meio de práticas sociais (FAIRCLOUGH, 1992/2001) que, simbolicamente, dispõem o mundo em significaçōes. Essas práticas do discurso contribuem para desenhar as "identidades" dos indivíduos e suas relações sociais, bem como suas representações e seus conhecimentos. Sendo assim, a conexão poder-ideologia é fundamental para compreender as dimensões sociais e culturais de nosso mundo.

As ideologias (FAIRCLOUGH, 1992/2001) devem ser entendidas como significações/construções da realidade - o mundo físico, as relações sociais e suas identidades - que arquitetam dimensões das formas/sentidos das práticas discursivas, contribuindo para a produção, para a reprodução ou para a transformação das relações de dominação. As práticas discursivas traduzem a dimensão do uso da linguagem que envolve os processos de produção, distribuição e consumo dos textos, variando de acordo com os tipos de discursos e fatores sociais.

Por isso, Fairclough (1992/2001) compreende as práticas discursivas à luz de uma perspectiva dialética. Dito de outra forma, não é seu objetivo apagar a história que descortina quão dominante tem sido o papel exercido pela sociedade sobre o sujeito que dela faz parte, silenciando-o, oprimindo-o, assujeitando-o das mais diversas formas e nos mais diferentes lugares. Por outro lado, Fairclough (1992/2001) não esquece o papel do processo criativo de mudança que as práticas discursivas exercem na sociedade. Essa superação das práticas discursivas reprodutoras pode constituir "ameaça” para aqueles que detêm o poder, criando tensões entre as forças convencionais e as criativas. Portanto, não basta, dentro desse viés, revelar processos dicotômicos e estanques, mas, principalmente, torná-los evidentes.

Nessa visão crítica se advoga que as práticas sociais não são mera relação de causa e efeito. Antes, são fruto do exercício do poder que se apresenta na linguagem em uso. Fairclough (1992/2001), com base em Foucault (1975/2004), sublinha que o poder é um fenômeno dinâmico não fixo e muito menos alocado exclusivamente a um grupo dominante. O poder, nesse caso, é compreendido como uma rede dinâmica de articulação em que os sujeitos podem se submeter ao poder hegemônico, podendo igualmente se tornar agentes questionadores desse mesmo poder. 
Fairclough (1992/2001) pontua que há duas maneiras de articulação do poder: o poder no discurso - lugar em que as relaçōes são exercidas e articuladas - e o poder por meio do discurso - a exemplo das ordens do discurso e instituiçôes que compartilham relaçôes de poder. Em resumo, o poder não está vinculado a um sujeito ou instituição, mas se organiza em redes de linguagem construídas pelos atores sociais em diferentes situaçōes sócio-históricas.

É dessa maneira que podemos entender o texto, objeto deste artigo, como um dispositivo ${ }^{2}$ que constrói discursos que podem propagar sentidos fixos dos sujeitos. Seja exemplo o significado de feminilidade e de masculinidade em nossa sociedade. Isso ocorre especialmente porque o texto integra uma das principais revistas formadoras de opinião neste país. Daí, um veículo de comunicação que assume alguns princípios ideológicos que podem restringir a produção de algumas práticas sociais, ampliando outras. É dentro dessa compreensão que o texto de nossa análise é produzido e pode ser interpretado de acordo com as relações hegemônicas de poder que posicionam os sujeitos em determinados espaços discursivos.

Com base na visão teórica oriunda da relação gênero-linguagem (MOITA LOPES, 2002; BUTLER, 1990/2006) e da orientação de linguagem de Fairclough (1992/2001), procura-se compreender, neste artigo, o discurso de um texto da revista Veja, dizente da sexualidade e do gênero, decorrência de práticas discursivas que legitimam convençōes e reproduzem as condições de produção binárias do que seja feminilidade e masculinidade. São essas práticas que geram ideologias hábeis para sustentar percepçôes do mundo essencialistas que impõem ideias e atitudes, muitas vezes imperceptíveis, contrárias aos indivíduos que desafiam o discurso hegemônico. São essas mesmas ideologias, inseridas em um momento histórico, que colaboram na construção dos papéis de masculinidade e feminilidade.

Os meios de comunicação de massa, por sua vez, como instituição social, são importantes dispositivos propagadores do binarismo (homem e mulher, heterossexual e homossexual), a cooperar para a manutenção de uma lógica

\footnotetext{
${ }^{2}$ Dispositivo para Foucault é "um conjunto decididamente heterogêneo que engloba discursos, instituições, organizações arquitetônicas, decisões regulamentares, leis, medidas administrativas, enunciados científicos, proposiçôes filosóficas, morais, filantrópicas. Em suma, o dito e o não dito são os elementos do dispositivo. O dispositivo é a rede que se pode estabelecer entre esses elementos". (FOUCAULT, $1984 / 2009$, p. 244)
} 
de dominação-exclusão. Dessa maneira, não é raro observar ações sexistas em programas de humor, em novelas, em artigos de revistas populares brasileiras, seja pelo reforço da ênfase nos papéis sociais - intensificando atitudes, essencialmente masculinas ou femininas -, seja ainda pela rejeição dessas ações - mediante um discurso multicultural que apenas promove o exotismo sem, no entanto, questionar as matrizes sociais, políticas e culturais das diferenças. Assim, intui-se que o cenário dos meios de comunicação parece silenciar-se diante das identificações ditas não naturais.

\section{Discurso e sexualidade na mídia}

Segundo Moita Lopes (2006), a tematização das masculinidades é assunto bastante recorrente na mídia, dadas as mudanças sociais, políticas e culturais que rodeiam a questão de gênero na atualidade. Essas transformações decorreram principalmente dos movimentos feministas que levaram milhares de mulheres ao mercado de trabalho, convergindo para a alteração no núcleo familiar que passa frequentemente a ser composto apenas por um pai ou por uma mãe, ou quando não por duas mães ou dois pais. Além, é claro, das modificações em relação ao sexo com anticoncepcionais que preveniram a gravidez, possibilitando que mulheres pudessem visualizar a sexualidade sob a égide do prazer.

Diante desse quadro, cada vez mais se tornou questionável a educação tradicional que encapsulava indivíduos em padrôes secularmente construídos. A mídia tem demonstrado interesse, recorrendo a histórias de sujeitos que vivem essa nova configuração social.

Pesquisas recentes (MOITA LOPES, 2006; 2009) têm chamado nossa atenção para o papel da mídia na manutenção de um discurso heteronormativo no concernente às diferenças de gêneros. Em alguns momentos, esses veículos de comunicação tendem a negar a existência ou a reforçar um tipo estereotipado de masculinidade e de feminilidade por meio de imagens de mulheres sensuais e magras, de um lado, de homens atleticamente másculos, de outro.

Os meios de comunicação, portanto, acabam fomentando a visão de que todos vivem sob um mesmo padrão sexual (LOURO, 2000). Contudo, constantemente essa situação é rompida, evidenciando que essas fronteiras não podem ser de todo controladas. Ao perceber esse fato, a instituição midiática se habilita a reagir com dispositivos que procuram regular, ordenar e disciplinar qualquer pessoa que possa provocar perturbações ao discurso hegemônico. 
Não obstante, quando a mídia toca na questão de sexualidade, o assunto sempre é visto como fenômeno puramente sexual, como se as identidades de gênero fossem, a priori, definidas como algo natural e não performático, a depender do contexto sócio-histórico (BUTLER, 1990/2006). Posto assim, qualquer menção a outras formas de identificação, que não a normativa, deve ser rejeitada. Dessa forma, aqueles que concordam com esse posicionamento não percebem que mesmo o discurso hegemônico de masculinidade e feminilidade não é algo factual, configurando uma construção histórico-social. Não sendo algo natural, podemos entender por que a figura da feminilidade e da masculinidade se revestiu de contornos diferentes em certas épocas e em certas culturas. Só poderemos compreender melhor essa questão se tivermos em mente que as identidades sexuais são caracterizadas e diferenciadas uma das outras por meio do discurso.

Fairclough (1992/2001) advoga que a categoria discurso vem sendo amplamente utilizada por teóricos sociais de várias correntes (FOUCAULT, 1975/2004; BUTLER, 1990/2006; HALL, 1997/2000). O que aproxima esses pensadores é a compreensão da linguagem como discurso inscrito e constitutivo de um contexto sócio-histórico. Em decorrência dessa visão, entendemos que as relações humanas são mediadas constantemente por lutas de poder que nem sempre se evidenciam transparentes para aqueles envolvidos nessas questôes.

É pelo discurso que elegemos a maneira de nomear as coisas que estão à nossa volta, assinalamos as diferenças, criamos símbolos de unidade $\mathrm{e}$ identificação coletiva, apagamos vozes e eternizamos outras. Desse ponto de vista, podemos compreender por que discursos heteronormativos procuram buscar explicações naturais sobre os limites entre masculinidade e feminilidade. Pelo olhar discursivo, percebemos que a legitimação heterossexual não ocorre aleatoriamente, antes, é fruto de um jogo hegemônico ideologicamente construído, que estabelece regras de como devemos nos comportar e movimentar em nosso teatro social. Aqueles que fracassam no script estabelecido são indigitados como anormais. Diante dessa perspectiva, podemos intuir o porquê do medo da presença do diferente, uma vez que parece pôr em questionamento os sentidos históricos do que seja normalidade. A bem dizer, isso significa deslocamento de forças e de poder. 


\section{Construção discursiva de sexualidade e de gênero}

O texto de Fernanda Allegretti pode ser um exemplo de como a mídia filtra os sentidos em torno da questão de gênero. No título do texto, "Educados no sexo neutro", o enunciador, de pronto, entreabre uma estranha provocação para aqueles enveredados nas questôes de linguagem e sexualidade. É possível a neutralidade?

A resposta a nosso questionamento é aclarada logo em seguida, no subtítulo do texto: "Uma corrente pedagógica defende a tese de que meninos e meninas devem ser criados de forma igual. O perigo é confundi-los acerca de sua sexualidade". Nesse trecho, o enunciador parece demonstrar seu posicionamento assentado no discurso binário (menino e menina), como se fossem pacíficas as duas categorias (SEDWICK, 1990/2008).

O texto configura trazer como sinônimo sexo biológico - anatomia interna e externa do corpo - e práticas sociais de gênero - papéis culturais e históricos do sujeito -, como se as fronteiras entre eles não fossem instáveis e as pessoas já fossem definidas como pertencentes a esse ou àquele grupo identitário. Por esse ponto de vista, as fronteiras sociais de gênero são demarcadas como algo próprio do sujeito, portanto imutável, ou, então, uma deformidade patológica. Significa dizer que o indivíduo que se identifica claramente com alguém do mesmo sexo encarna uma ameaça, provocando medo.

O enunciado também parece postular que qualquer processo educativo mais igualitário em relação ao gênero poderia provocar enganos com relação aos papéis sociais dos sujeitos sexuados (LOURO, 2000). Essa afirmação figura ser expressa pelo léxico "perigo" e pelo verbo "confundir", que procuram advertir o leitor sobre o desconforto da não atribuição de valores socialmente aceitos sobre o comportamento feminino e masculino.

Tal reação pode evidenciar quanto as composiçōes de sentido diante da temática sexual são cruzadas pelas normas da heteronormatividade (WARNER, 1991), pois essas regras não são tácitas e precisam ser constantemente relembradas para que o sujeito as internalize. Daí, tal situação é declarada no texto como incômoda e desordeira ao discurso hegemônico de sexualidade.

Para sustentar o pressuposto do "perigo" e da "confusão", o enunciador intenta defender uma subjetividade genealógica normativa que remete, inevitavelmente, ao discurso essencialista (MOITA LOPES, 2009). Esse discurso busca construir, por meio de vozes de "especialistas", uma versão científica que explique as consequências duvidosas de uma "educação neutra", como podemos perceber no fragmento que segue: 
A educação de gênero neutro abriga um objetivo nobre que, para ser alcançado, exige práticas arriscadas. A ideia dos que advogam essa corrente pedagógica é eliminar de uma vez por todas os velhos padrões que põem a mulher como dona de casa e o homem como o macho provedor, a mulher como o ser delicado que atende às vontades masculinas e cuida da prole. A liberdade de escolha para inverter os papéis tradicionais, para quem segue essa corrente, é um exemplo positivo na educação dos filhos. O risco dessa postura, alertam muitos especialistas, é confundir as crianças acerca de sua sexualidade, com consequências imprevisíveis. "Ampliar as possibilidades de aprendizado é uma ideia interessante, mas forçar a transição entre os universos masculino e feminino, não", diz a psicanalista paulista Ana Olmos, especializada em neuropsicologia infantil. (ALLEGRETTI, 2012, p.94).

Nesse excerto, o enunciador, imbuído de um discurso multicultural, percebe a importância de uma possível educação não regida pela desigualdade de gênero - "a educação de gênero neutro abriga um objetivo nobre que, para ser alcançado, exige práticas arriscadas”. Contudo, sua constatação parece pairar sob um plano ainda onírico, que diferencia homens e mulheres sem promover uma discussão mais política e, por acréscimo, mais abrangente. Pelo contrário, qualquer forma de revisão de práticas sociais consagradas é vista como "arriscada".

A voz da psicanalista, nesse fragmento, é utilizada como elemento que acentua o argumento de rejeição da suposta "inversão" dos papéis sociais entre homens e mulheres. O uso das palavras "forçar" e "transição", juntamente com o advérbio "não", cria uma imagem negativa em relação a tal ocorrência. Portanto, ao utilizar o olhar científico representado na figura da especialista, o texto da revista intenta estabelecer um regime de verdade (FOUCAULT, 1975/2004) que procura explicações, numa dada produção de conhecimento, justificativas para o equívoco de uma educação mais sensível à questão de gênero. Essa posição indica um saber já constituído por determinada comunidade científica com paradigmas padronizantes, que se apresenta como o único possível.

De certo modo, tal depoimento tropeça em um discurso hegemônico que procura enquadrar os sujeitos em uma identidade adequada a seu corpo biológico (LOURO, 2000). Embora ele seja o local da sexualidade, estabelecendo os limites dos possíveis, a sexualidade humana se apresenta muito além do corpo: somam-se os desejos, as ideologias e as fantasias que evidenciam como o corpo e o gênero são constitutivos em um contexto sócio-histórico (BUTLER, 1990/2006). 
Pensar sexualidade como sinônimo de corpo biológico é pôr em evidência que a heteronormatividade é a única norma que regula e descreve a orientação sexual. Trata-se, segundo Warner (1991), de reforçar o discurso hetero como organizador da sexualidade, transformando-o em instituição reguladora e privilegiada da organização sexual humana. Essa regularização se materializa pelos discursos de diferentes segmentos, como é o caso da mídia que busca naturalizar os pressupostos heteronormativos.

Qualquer sinal de afastamento dessa aparente normalidade pode ser entendido como anomalia. Daí, talvez, a opção em trazer o depoimento de um suposto profissional da área de saúde, hábil, a insinuar a necessidade de práticas psicoterapêuticas para os possíveis desviantes que poderiam se confundir diante de uma educação sob a égide da "neutralidade sexual" - "o risco dessa postura, alertam muitos especialistas, é confundir as crianças acerca de sua sexualidade, com consequências imprevisíveis". Certamente, uma das consequências, aludida pela especialista, é a possível patologia de distúrbio sexual que poderia se insurgir diante da confusão infantil. É interessante observar que, constantemente, o discurso normativo lança mão dessa prerrogativa como argumento que justifica seu desconforto moral.

Um exemplo de comportamento inadequado que essa inversão de papéis patrocinada pelos pais pode provocar tornou-se público com o casal de atores americanos Angelina Jolie e Brad Pitt. Eles dizem criar sua filha Shiloh, hoje com 6 anos, dentro das normas da educação de gênero neutro. Angelina já foi vista comprando roupas de menino para Shiloh. Permite que a menina use gravata, sapatos masculinos e cortes de cabelo idem. A atriz costuma se desentender com a sogra, que insiste em presentear a neta com roupas femininas e fantasias de princesa. O resultado é que o lindo bebê que aparecia no colo de Angelina em seu primeiro ano de vida hoje surge nas fotos com a aparência masculinizada. Disse à VEJA a psicóloga americana Diane Ehrensaft, diretora do Centro de Saúde Mental e Gênero da Criança e do Adolescente, na Califórnia: "É comum que as crianças brinquem com peças de roupa do sexo oposto, mas que os pais estimulem esse comportamento, isso definitivamente não é normal, muito menos saudável”. (ALLEGRETTI, 2012, p.94).

Se levarmos em conta que a criança é um sujeito social, envolvido em um sistema que constrói valores, seu corpo e atitudes são fruto desses objetos culturais. Nessa perspectiva, o enunciador parece querer sugerir que ela deveria assumir comportamentos considerados apropriados pela sociedade, dado que 
qualquer desvio dessa ordem pode ser entendido como inapropriado. No excerto apresentado, a educação ofertada pelos atores americanos Angelina Jolie e Brad Pitt a seus filhos soa esdrúxula. Ao utilizar o termo "inadequado", seguido da expressão "inversão de papéis", o enunciador parece se postar contrariamente a qualquer atitude que possa criar fissuras na uniformidade sexual vigente. Daí, talvez, a educação da filha do casal hollywoodiano possa ser vista como perigosa quebra da suposta unidade de gênero, na medida em que abraça outras performances de feminilidade que não a habitual - "Angelina já foi vista comprando roupas de menino para Shiloh. Permite que a menina use gravata, sapatos masculinos e cortes de cabelo idem." Instaura, portanto, uma inversão da lógica normativa que pode provocar possível mudança de papéis sociais.

Nesse caso, paira no ar o perigo da masculinização da criança - "o resultado é que o lindo bebê que aparecia no colo de Angelina em seu primeiro ano de vida hoje surge nas fotos com a aparência masculinizada". Como a mídia quase sempre adota uma política de homogeneização de comportamento, pouca tolerância resiste às práticas que sejam contrárias ao discurso vigente. Por isso, uma das estratégias de silenciamento dessas práticas é transformá-las em patologia para que o sujeito possa ser medicado e reconduzido à normalidade. Ao focalizar seu olhar para atitudes não heteronormativas da criança, procurando manter uma feminilidade hegemônica, o texto da revista acaba também pondo à mostra a possibilidade de deslocamento de gênero (BUTLER,1990/2006), dado que evidencia uma disposição antinormatizadora de desafios ao figurino regulador da sociedade, assumindo o desconforto da ambiguidade, do incômodo e da perturbação (LOURO, 2000). Nessa marcha, a oposição a um comportamento inadequado só pode existir se admite a produção de outros sentidos de gêneros, mesmo que se procure negá-los ou ignorá-los.

É digno de nota que o texto encarta, como argumento de autoridade, o discurso de uma diretora do Centro de Saúde Mental e Gênero da Criança e do Adolescente, insinuando uma dificuldade de ordem psicológica da atriz norte-americana em relação à condução da educação de sua filha - "é comum que as crianças brinquem com peças de roupa do sexo oposto, mas que os pais estimulem esse comportamento, isso definitivamente não é normal, muito menos saudável”. A essa luz, Angelina Jolie é vista como alguém pouco "saudável" e "normal", uma vez que apresenta outros modos de vida que fogem completamente ao enquadramento societário. 
Portanto, o texto nos convida a evidenciar quanto a compreensão sobre gênero é socialmente construída e mediada pelo poder. Não fosse assim, por que o temor apresentado no texto? De que forma uma educação mais igualitária de gênero poderia confundir meninos/as sobre seus atos performáticos sexuais? Em resposta a esse questionamento, percebe-se que o assunto não é, necessariamente, o problema em si. O problema mesmo é um possível traço de masculinidade que pode ser entendido como característica homoerótica no comportamento da filha de Angelina Jolie.

Até hoje a ciência não descobriu se a homossexualidade é inata ou adquirida no meio social, mas já se tem certeza de que toda criança nasce com predisposição a desenvolver características psicológicas do sexo a que pertence. A literatura médica está repleta de casos em que os pais tentaram dar outra orientação sexual aos filhos, com resultados lamentáveis. O caso recente mais conhecido é o do canadense David Reimer. Em 1966, antes de completar 1 ano, Reimer teve o pênis extirpado numa cirurgia de circuncisão desastrada. Seus pais cruzaram os Estados Unidos para consultar o psicólogo Jolin Money, na época, considerado uma autoridade em diferenças entre os gêneros. Money aconselhou uma cirurgia de mudança de sexo, com a construção de uma vagina artificial seguida de um bombardeio de hormônios femininos. Na ocasião, Money tentava comprovar a teoria de que não eram as características físicas que determinavam o sexo, e sim a educação dada pela família. Os pais concordaram com a cirurgia e Reimer, rebatizado de Brenda, foi criado como uma menina. Logo se constatou o fracasso da empreitada. Aos 2 anos, Reimer rasgava seus vestidos com raiva. Recusava-se a brincar com bonecas. Mais tarde, na escola, sofria bullying por causa de seus trejeitos masculinos. Seus pais só lhe contaram sobre a cirurgia de mudança de sexo aos 14 anos. Em 2004, aos 38 anos, Reimer se matou. (ALLEGRETTI, 2012, p.94).

Frequentemente, a mídia revela profunda indisposição em apreender uma cultura que reconhece a pluralidade de gênero e enfrentar o fato de que ela é marcada tanto pela estigmatização quanto pelo preconceito. Sendo assim, por que insinuar que a educação de uma criança poderá afetar seu desejo sexual? Quantas mulheres e homens, em nossa sociedade, se apresentam ora mais masculinos ora mais femininos sem, no entanto, traduzir preferência por alguém do mesmo sexo? O que nos parece é que se manifesta um medo em relação à homossexualidade. Talvez, por essa razão, o enunciador aluda insistentemente a um argumento de "base científica" - "até hoje a ciência não descobriu se a homossexualidade é inata ou adquirida no meio social, mas já se tem certeza de 
que toda criança nasce com predisposição a desenvolver características psicológicas do sexo a que pertence" - para justificar seu posicionamento.

A que ciência se refere? Pelas escolhas lexicais ("não descobriu", "inata", "predisposição", "literatura médica”), o enunciador se reporta ao pensamento positivista e patológico para corroborar seu discurso heteronormativo. Observa-se, de igual parte, que o enunciador se esforça por descrever a sexualidade humana como um fenômeno ligado ao órgão genital - "toda criança nasce com predisposição a desenvolver características psicológicas do sexo a que pertence" -, como se a identidade de gênero fosse definida como algo natural e não performático (BUTLER, 1990/2006).

$\mathrm{Na}$ tentativa de convencer o leitor sobre seu ponto de vista, o enunciador busca exemplos atípicos na literatura médica a pretexto de mostrar as consequências funestas de qualquer alteração educacional que vise a qualquer mudança no panorama da discussão que orbite o gênero - "a literatura médica está repleta de casos em que os pais tentaram dar outra orientação sexual aos filhos, com resultados lamentáveis". Contudo, não nos parece que a filha do casal hollywoodiano tenha uma orientação sexual "diferente" das demais crianças. Pelo que o próprio enunciador descreve, a mãe apenas permite que sua filha utilize artefatos considerados mais masculinos. Não é claro, em momento algum, ao longo do enunciado, que há um incentivo para alteração de comportamento sexual da menor. Diferentemente se deu com David Reimer, descrito pelo próprio texto, o qual teve seu pênis extirpado em uma cirurgia, depois reconduzido a assumir uma identificação feminina à sua revelia.

Trazer uma situação tão generalizadora - como é o caso de David Reimer -, a título de exemplo das consequências de uma educação não normativa, parece-nos uma tentativa de o enunciador deflagrar uma profilaxia em relação àqueles que possam fomentar alguma manifestação de simpatia por algum comportamento fora do padrão estabelecido. Fairclough (1992/2001) nos adverte de que a ideologia hegemônica, por meio do exercício do poder, constrói fatos que são dados como universais e comuns. $\mathrm{O}$ sofrimento e a morte de David Reimer - "mais tarde, na escola, sofria bullying por causa de seus trejeitos masculinos. Seus pais só lhe contaram sobre a cirurgia de mudança de sexo aos 14 anos. Em 2004, aos 38 anos, Reimer se matou" - são exemplos dessas generalizaçóes e das possíveis consequências daqueles que comungam com uma fuga da relação binária de gênero (BUTLER, 1990/2006).

O enunciador, para manter sua oposição à ideia de uma educação que não admite multiplicidade de sentido para a questão do gênero, diligencia por tecer argumentos comparativos de ordem econômica, cultural, social e 
educacional. $\mathrm{O}$ intuito é justificar a ineficiência de tal posicionamento no contexto brasileiro.

Não é de admirar que a Suécia seja o território onde a educação de gênero neutro melhor viceja. O país figura em quarto lugar no ranking do Fórum Econômico Mundial, que mede as diferenças entre os homens e as mulheres levando em conta o nível de remuneração e o acesso à saúde, à educação e a cargos políticos. O Brasil ocupa a $62^{a}$ posição nessa lista. "Os adultos precisam definitivamente mudar de mentalidade para que as crianças entendam que homens e mulheres têm a mesma capacidade e os mesmos direitos", diz a professora Hanna Grandert, de 33 anos, que mora em Estocolmo com o marido, Tobias Egge, de 43. O casal educa os quatro filhos, uma menina e três meninos, sem distinção de gênero. Hanna leciona na escola pública Egalia, fundada há dois anos e que segue a mesma linha pedagógica. $\mathrm{Na}$ Egalia, os alunos não são chamados pelo equivalente em sueco a "ele" e "ela", mas pelo pronome neutro hen. Dificilmente se veria algo semelhante no Brasil. Diz Laez Fonseca, assessor pedagógico do Colégio São Luís, de São Paulo: "Hoje as escolas são mistas, e nelas se procura eliminar os aspectos culturais machistas. Mas é preciso considerar que homens e mulheres são biologicamente diferentes". (ALLEGRETTI, 2012, p.94).

A voz que enuncia procura reforçar a impossibilidade de uma prática educacional menos ortodoxa no contexto brasileiro por meio da comparação entre um país rico (Suécia) e o Brasil. Ao pôr em confronto essas duas realidades, o enunciador intenta diferenciar dando ênfase à questão econômica - "não é de admirar que a Suécia seja o território onde a educação de gênero neutro melhor viceja. O país figura em quarto lugar no ranking do Fórum Econômico Mundial, que mede as diferenças entre os homens e as mulheres levando em conta o nível de remuneração e o acesso à saúde, à educação e a cargos políticos". Essa estratégia discursiva consiste em buscar explicações racionais (THOMPSON, 1995/2002) com um apelo ao "bom-senso" como forma de legitimação do ponto de vista do enunciador. Em assim fazendo, procura operacionalizar o modus operandi que enfeixa justificativas lógicas para inviabilizar a posição da "educação de gênero neutro", disseminando, dessa forma, discursos hegemônicos sobre o feminino e o masculino.

A justificativa racional do enunciador parece traçar uma série de diferenças entre os dois países. A primeira é de ordem social. Neste caso, o enunciador procura, por meio de um discurso direto de uma professora adepta da "educação neutra" - "os adultos precisam definitivamente mudar de 
mentalidade para que as crianças entendam que homens e mulheres têm a mesma capacidade e os mesmos direitos" -, evidências para a impossibilidade de tal movimento educativo no Brasil. Ao apresentar esse discurso, o enunciador figura deixar transparecer que, em um país machista e marcado pelas diferenças sociais, como é o nosso, dificilmente haveria uma "mudança de mentalidade dos adultos".

A segunda diferença é de ordem linguística - "na Egalia, os alunos não são chamados pelo equivalente em sueco a "ele" e "ela", mas pelo pronome neutro hen" -, que procura revelar quão complexa é a operacionalização de tais alteraçóes no interior do ambiente educacional brasileiro. Na língua portuguesa, por exemplo, podemos pensar, como sugere o enunciador, que não temos sequer um pronome neutro que poderia promover essa igualdade de escolha linguística. A despeito dessa situação, o enunciador, por último, busca trazer a voz de um assessor pedagógico de uma instituição religiosa. Aliás, essa opção não nos parece desprovida de sentido. A religião, associada à escola, historicamente, sempre foi uma instituição de negação à existência das identidades de gêneros diferentes (JESUS, 2012a, 2012b). O discurso do assessor, como não poderia deixar de ser, leva em conta que as escolas brasileiras procuram expurgar qualquer atitude machista - "hoje as escolas são mistas, e nelas se procura eliminar os aspectos culturais machistas. Mas é preciso considerar que homens e mulheres são biologicamente diferentes". As pesquisas recentes (LOURO, 2000; LIVIA; HALL, 2010; LOUTZENHEISER; MOORE, 2009/2011;JESUS, 2012a, 2012b;), ao contrário, nos advertem de que a escola persiste em um jogo segregador, ideologicamente construído, que estabelece regras de como devemos nos portar como homens e mulheres, atentando sempre à nossa conformação genital.

Esses enunciados apenas patenteiam que o texto é permeado por discursos essencialistas, levando em linha de conta que eles são práticas sociais articuladas dentro de um plano histórico, sociopolítico e ideológico. Tais discursos, portanto, não significam necessariamente que são verdadeiros. Em contrário disso, são reveladores do posicionamento ideológico do sujeito.

\section{Reflexões finais}

Neste artigo, buscou-se analisar o discurso sobre sexualidade e gênero em um texto veiculado na revista Veja. A partir desta análise, colhe-se que os enunciados apresentados podem ser interpretados como um discurso disciplinador (FOUCAULT,1975/2004) das relações de gênero, dada a postura essencialista e normativa que o texto assume em seu discurso. 
Com este trabalho, percebe-se que o texto utiliza discursos que se esforçam por explicar qualquer manifestação de gênero contrária ao convencional sob um viés patológico, por meio de vozes de profissionais da saúde que desautorizam qualquer educação que possa pôr em xeque o discurso hegemônico. Dessa forma, o texto se mostra eficaz dispositivo regulador de comportamento de gênero, na medida em que procura silenciar formas não canônicas de expressão do feminino e do masculino. Pela popularidade da revista Veja, o texto colabora para compor o discurso normatizador que procura alimentar o imaginário popular.

Posto dessa forma, os sentidos apresentados no texto da revista podem ser entendidos como elementos que colaboram na construção de um pensamento heteronormativo, à medida que não acolhem possibilidades outras que não sejam o padrão hegemônico de comportamento sexual. Esse discurso é fundamentado em uma lógica binária que procura evidenciar o estranho com caracterizaçóes generalizadoras ou estereotipadas como forma de expurgo social. Ao produzir esses sentidos asseguram a manutenção de identificações homogêneas e fixas. Disso podem resultar ações geradoras de atitudes que fomentem a discriminação contra aqueles considerados diferentes.

Ao gerar esses sentidos, o artigo analisado procura expor a questão da diferença de gêneros como algo perigoso. Daí utilizar, na linha da estratégia argumentativa, a negação como mecanismo que desautoriza qualquer forma híbrida de identificação. Esse tipo de operação busca, entre outras coisas, aniquilar a heterogeneidade, o conflito, o antagonismo próprio da experiência humana. Essa constatação tem consequência política à proporção que desconsidera um sujeito diferente do pensamento hegemônico.

No âmbito educacional, o texto analisado parece insinuar que a escola tem com função, entre outras, a autodisciplinação dos sujeitos no tocante à questão de gênero. Levando isso em consideração, o espaço escolar, nesse caso, acaba se tornando ambiente de promoção de um discurso heteronormativo que deve legitimar apenas uma posição social.

Se atentarmos às consequências políticas e educacionais pinçadas no texto que compôs o corpus deste estudo, pode ser notada a necessidade premente de revisitar esse discurso que parece pretender engajar seus leitores em práticas discursivas homogêneas, marcadas pelas tradicionais fronteiras legitimadoras de uma cultura sexual heteronormativa.

No campo dos estudos queer, este trabalho não teve a pretensão de explicitar a complexidade do campo teórico, mas refletir sobre alguns de seus 
princípios, particularmente aqueles que se revelaram úteis à pesquisa. Esse diálogo se apresenta frutífero, especialmente para aqueles interessados na questão da linguagem, do discurso e da sexualidade.

Como resultado desta pesquisa, evidenciou-se para nós que precisamos questionar os discursos acerca das relações de gênero na mídia para que venhamos a perceber a ideologia que está implícita em seus dizeres. Acreditamos que futuras pesquisas precisariam entender melhor a recorrência das representações do feminino e do masculino em outros textos da revista Veja, em especial pelo alcance político que ela encerra como formadora de leitores.

\section{Referências}

ALLEGRETTI, F. Educados no sexo neutro: uma corrente pedagógica defende a tese de que meninos e meninas devem ser criados de forma igual. O perigo é confundilos acerca de sua sexualidade. Revista Veja, Editora Abril, ed. 2.300, n.51, p.93-94, 19 dez. 2012.

BUTLER, J. Gender trouble: feminism and the subversion of identity. New York and London: Routledge Classics, 1990/2006.

FAIRCLOUGH, Norman. Discurso e mudança social. Trad. Izabel Magalhães, Editora da UNB, 1992/ 2001.

FOUCAULT, M. Vigiar e Punir: nascimento da prisão. Trad. Raquel Ramalhete, 28. Ed. Petrópolis, 1975/2004.

FOUCAULT, M . História da sexualidade I: a vontade de saber. Trad. Maria Thereza da Costa Albuquerque, 10. ed. São Paulo: Graal, 1984/2009.

HALL, S. Quem precisa de identidade? In: SILVA, T.T; HALL, S.; WOODWARD, K. (Org.). Identidade e diferença: a perspectiva dos estudos culturais. Tradução: Tomáz Tadeu da Silva. Petrópolis, RJ: Editora Vozes, 1997/2000, p.103-133.

HIGHTOWER, M. W. Masculinidade e educação. In: APPLE, M. W; AU, W.; GANDIN, L. A. Educação crítica: análise internacional. Trad. Vinicius Figueira, Porto Alegre: Artmed, 2009/2011, p.188-202.

JESUS, D. M. Homofobia na sala de aula digital: representaçôes de professores em fórum de discussão on-line. In: SOUZA, L. L. de; ROCHA, S. A. (Org.). Formação de educadores, gênero e diversidade. Cuiabá: EdUFMT, 2012a, v.1, p.165-180.

JESUS, D. M. Gender and language teacher education in a Brazilian context. Polifonia, Cuiabá: EdUFMT, v.19, p.153-163, 2012 b. 
LIVIA, A.; HALL, K. "É uma menina!": a volta da performatividade à linguística. In: OSTERMANN, A. C.; FONTANA, B. (Org.). Linguagem, gênero, sexualidade: clássicos traduzidos. São Paulo: Parábola, 2010. p.109-127.

LOURO, G. L. Currículo, gênero e sexualidade. Porto, Portugal: Porto Editora, 2000.

LOUTZENHEISER, L. W.; MOORE, S. D. M. Escolas seguras, sexualidades e educação crítica. In: APPLE, M. W.; AU, W.; GANDIN, L. A. Educação crítica: análise internacional. Trad. Vinícius Figueira, Porto Alegre: Artmed, 2009/ 2011. p.173-202.

MOITA LOPES, L. P. (Org.). Identidades fragmentadas: a construção discursiva de raça, gênero e sexualidade na sala de aula. Campinas, S.P: Mercado de Letras, 2002. MOITA LOPES, L. P. Falta homem até pra homem: a construção da masculinidade hegemônica no discurso midiático. In: HEBERLE, V. M.; OSTERMANN, A. C.; FIGUEIREDO, D. C. (Org.). Linguagem e gênero no trabalho, na mídia e em outros contextos. Florianópolis: Editora da UFSC, 2006. p. 131-157.

MOITA LOPES, L. P. A performance narrativa do jogador Ronaldo como fenômeno sexual em um jornal carioca. Revista da ANPOLL, v. 2, n. 27, p.128-157, 2009.

SEDWICK, E. K. Epistemology of the closet. Berkeley/Los Angeles/ London: University of California Press, 1990/2008.

THOMPSON, J. Ideologia e cultura moderna: teoria social crítica na era dos meios de comunicação de massa. Trad. Pedrinho A. Guareschi. Petrópolis: Vozes, $1995 / 2002$.

WARNER, M. Introduction: fear of a queer planet. Social Text 9, n.29, p.3-12, 1991.

WEEKS, J. O corpo e a sexualidade. In: LOURO, G. L. (Org.). O corpo educado: pedagogias da sexualidade. Belo Horizonte: Autêntica, 1999. 


\section{ANEXO 1}

\section{EDUCADOS NO SEXO NEUTRO}

Uma corrente pedagógica defende a tese de que meninos e meninas devem ser criados de forma igual.

O perigo é confundi-los acerca de sua sexualidade.

Fernanda Allegretti

As filiais das lojas de brinquedos Toys"R”Us e BR Toys na Suécia trazem uma novidade em seus catálogos deste Natal. As fotos ilustrativas mostram meninas com carrinhos e armas de mentira e meninos se divertindo com bonecas e utensílios domésticos, como aspirador de pó e ferro de passar roupas. A troca de papeis nas fotos foi feita sob a orientação da Swedish Advertising Ombudsman, uma das organizações que regulam a propaganda na Suécia. O órgão alega que, no ano passado, recebeu muitas reclamaçôes de consumidores dizendo que as campanhas dessas lojas eram muito conservadoras em relação aos papeis feminino e masculino. Por que -argumentavam esses consumidores - manter velhos estereótipos ligados ao gênero das crianças ao escolher os brinquedos para elas? Esse tipo de raciocínio não é uma excentricidade restrita aos suecos. Ele faz parte de uma corrente pedagógica que vem se espalhando por outros países e que propõe uma educação de gênero neutro, ou seja, que não leve em consideração o sexo da criança. Os educadores e as famílias que defendem esse estilo de aprendizado afirmam que é preciso derrubar tradiçôes como vestir meninos de azul e meninas de cor-de-rosa, e que se deve dar a eles liberdade para que escolham as roupas que vão usar - mesmo que sejam características do sexo oposto. Segundo esse ponto de vista, não se deve influenciar a criança a adotar comportamentos que sempre foram vistos como típicos de seu sexo.

A educação de gênero neutro abriga um objetivo nobre que, para ser alcançado, exige práticas arriscadas. A ideia dos que advogam essa corrente pedagógica é eliminar de uma vez por todas os velhos padrões que põem a mulher como dona de casa e o homem como o macho provedor, a mulher como o ser delicado que atende às vontades masculinas e cuida da prole. A liberdade de escolha para inverter os papeis tradicionais, para quem segue essa corrente, é um exemplo positivo na educação dos filhos. O risco dessa postura, alertam muitos especialistas, é confundir as crianças acerca de sua sexualidade, com consequências imprevisíveis. 
"Ampliar as possibilidades de aprendizado é uma ideia interessante, mas forçar a transição entre os universos masculino e feminino, não", diz a psicanalista paulista Ana Olmos, especializada em neuropsicologia infantil.

Um exemplo de comportamento inadequado que essa inversão de papéis patrocinada pelos pais pode provocar tornou-se público com o casal de atores americanos Angelina Jolie e Brad Pitt. Eles dizem criar sua filha Shiloh, hoje com 6 anos, dentro das normas da educação de gênero neutro. Angelina já foi vista comprando roupas de menino para Shiloh. Permite que a menina use gravata, sapatos masculinos e cortes de cabelo idem. A atriz costuma se desentender com a sogra, que insiste em presentear a neta com roupas femininas e fantasias de princesa. $\mathrm{O}$ resultado é que o lindo bebê que aparecia no colo de Angelina em seu primeiro ano de vida hoje surge nas fotos com a aparência masculinizada. Disse à Veja a psicóloga americana Diane Ehrensaft, diretora do Centro de Saúde Mental e Gênero da Criança e do Adolescente, na Califórnia: "É comum que as crianças brinquem com peças de roupa do sexo oposto, mas que os pais estimulem esse comportamento, isso definitivamente não é normal, muito menos saudável.”

Até hoje a ciência não descobriu se a homossexualidade é inata ou adquirida no meio social, mas já se tem certeza de que toda criança nasce com predisposição a desenvolver características psicológicas do sexo a que pertence. A literatura médica está repleta de casos em que os pais tentaram dar outra orientação sexual aos filhos, com resultados lamentáveis. O caso recente mais conhecido é o do canadense David Reimer. Em 1966, antes de completar 1 ano, Reimer teve o pênis extirpado numa cirurgia de circuncisão desastrada. Seus pais cruzaram os Estados Unidos para consultar o psicólogo Jolin Money, na época, considerado uma autoridade em diferenças entre os gêneros. Money aconselhou uma cirurgia de mudança de sexo, com a construção de uma vagina artificial seguida de um bombardeio de hormônios femininos. Na ocasião, Money tentava comprovar a teoria de que não eram as características físicas que determinavam o sexo, e sim a educação dada pela família. Os pais concordaram com a cirurgia e Reimer, rebatizado de Brenda, foi criado como uma menina. Logo se constatou o fracasso da empreitada. Aos 2 anos, Reimer rasgava seus vestidos com raiva. Recusava-se a brincar com bonecas. Mais tarde, na escola, sofria bullying por causa de seus trejeitos masculinos. Seus pais só lhe contaram sobre a cirurgia de mudança de sexo aos 14 anos. Em 2004, aos 38 anos, Reimer se matou.

Não é de admirar que a Suécia seja o território onde a educação de gênero neutro melhor viceja. O país figura em quarto lugar no ranking do Fórum Econômico Mundial, que mede as diferenças entre os homens e as mulheres, 
levando em conta o nível de remuneração e o acesso à saúde, à educação e a cargos políticos. O Brasil ocupa a $62^{a}$ posição nessa lista. "Os adultos precisam definitivamente mudar de mentalidade para que as crianças entendam que homens e mulheres têm a mesma capacidade e os mesmos direitos", diz a professora Hanna Grandert, de 33 anos, que mora em Estocolmo com o marido, Tobias Egge, de 43. O casal educa os quatro filhos, uma menina e três meninos, sem distinção de gênero. Hanna leciona na escola pública Egalia, fundada há dois anos e que segue a mesma linha pedagógica. Na Egalia, os alunos não são chamados pelo equivalente em sueco a "ele" e "ela", mas pelo pronome neutro hen. Dificilmente se veria algo semelhante no Brasil. Diz Laez Fonseca, assessor pedagógico do Colégio São Luís, de São Paulo: "Hoje as escolas são mistas, e nelas se procura eliminar os aspectos culturais machistas. Mas é preciso considerar que homens e mulheres são biologicamente diferentes."

Data de submissão: 30/09/2013. Data de aprovação: 25/07/2014. 